Int. J. Electrochem. Sci., 12 (2017) 330 - 346

International Journal of

ELECTROCHEMICAL

SCIENCE

www.electrochemsci.org

\title{
Electrochemical Determination of Theophylline Pharmacokinetic under the Effect of Roxithromycin in Rats by the MWNTs/Au/poly-L-lysine Modified Sensor
}

\author{
Anlin Peng ${ }^{1,2}$, Hong Yan ${ }^{1}$, Caikui Luo ${ }^{1}$, Guangxian Wang ${ }^{1}$, Yuting Wang ${ }^{3}$,Xianzhi Ye ${ }^{1 *}$,Hong Ding ${ }^{2, *}$ \\ ${ }^{1}$ Department of Pharmacy, Wuhan No.3 Hospital, Wuhan 430072, China \\ ${ }^{2}$ Department of Pharmacy, Wuhan University, Wuhan 430072, China \\ ${ }^{3}$ Department of Cardiology, Heart Center at Puai Hospital, Puai Hospital, Huazhong University of \\ Science and Technology, Wuhan 430030, China \\ *E-mail: $155109859 @ q q . c o m$
}

doi: $10.20964 / 2017.01 .03$

Received: 5 September 2016 / Accepted: 19 October 2016 / Published: 12 December 2016

In this work, a novel and simple method for pharmacokinetic of theophylline in rats was described with modified sensor based on MWNTs/Au/poly-L-lysine. The modified screen-printed electrode exhibited excellent electrocatalytic activity towards the oxidation of theophylline in real biological samples. The optimum experimental conditions were explored by square wave voltammetry (SWV). The peak current of theophylline was proportional to the concentration in the range of $10 \mu \mathrm{M}$ to 200 $\mu \mathrm{M}$ with the detection limit $2.0 \mu \mathrm{M}$. Compared with the HPLC method, the newly proposed method also exhibited good results in the determination of theophylline pharmacokinetic under the effect of roxithromycin. The drug concentration-time curve of theophylline was also attained at different time points: $10 \mathrm{~min}, 20 \mathrm{~min}, 30 \mathrm{~min}, 60 \mathrm{~min}, 90 \mathrm{~min}, 120 \mathrm{~min}, 240 \mathrm{~min}$ and $480 \mathrm{~min}$. The results strongly showed that the established sensor could be applied to the real-time monitoring such as the clinical drug therapeutic drug monitoring, especially in the case of high concentration thepohylline intoxication.

Keywords: determination, theophylline, roxithromycin, pharmacokinetic, modified screen-printed electrode, the drug concentration-time curve

\section{$\underline{\text { FULL TEXT }}$}

(C) 2017 The Authors. Published by ESG (www.electrochemsci.org). This article is an open access article distributed under the terms and conditions of the Creative Commons Attribution license (http://creativecommons.org/licenses/by/4.0/). 